\title{
PENGARUH BAURAN PEMASARAN TERHADAP KEPUTUSAN PEMBELIAN DI GRAMEDIA MANADO
}

\section{THE INFLUENCE OF MARKETING MIX ON CONSUMER PURCHASE DECISION AT GRAMEDIA MANADO}

\author{
$\underline{\text { Desilsan Tansala }}^{(1)}$, Johny Revo Elia Tampi ${ }^{(2)}$, Joanne Valesca Mangindaan ${ }^{(2)}$
}

1) Peneliti Independen

2) Staf Pengajar dan Peneliti pada Program Studi Pengelolaan Sumberdaya Pembangunan Pascasarjana, Universitas Sam Ratulangi, Manado

*Penulis untuk korespondensi: desilsantansala9@gmail.com

Naskah diterima melalui Website Jurnal Ilmiah agrisosioekonomi@unsrat.ac.id

Jumat, 15 Januari 2021

Disetujui diterbitkan

Jumat, 22 Januari 2021

\begin{abstract}
This study aims to determine whether the marketing mix (products, prices, promotions, distribution places/channels, people, processes and physical facilities) simultaneously influence purchasing decision at Gramedia Manado. This research was conducted at Gramedia Bookstore, Jl. Sam Ratulangi No. 45, South Wenang, Manado City. This research was conducted from October to November 2020. This research is a quantitative study with a descriptive approach to see causal relationships. This study uses primary and secondary data. Primary data is the result of direct data collection from informants by distributing questionnaires to 100 respondents who have made at least two purchases at Gramedia Manado. Secondary data is obtained from existing sources (books, journals, websites, etc.) for reference in making reports. Data analysis used multiple regression analysis. The results showed that the marketing mix simultaneously had an effect and was significant on purchasing decisions at Gramedia Manado. ${ }^{*}{ }^{2}{ }^{*}$
\end{abstract}

Keywords: marketing mix, purchasing decision, consumer

\begin{abstract}
ABSTRAK
Penelitian ini bertujuan untuk mengetahui apakah bauran pemasaran (produk, harga, promosi, tempat/saluran distribusi, orang, proses dan sarana fisik) berpengaruh secara simultan terhadap keputusan pembelian di Gramedia Manado. Penelitian ini dilaksanakan di Toko Buku Gramedia, Jl. Sam Ratulangi No. 45, Wenang Selatan, Kota Manado. Penelitian ini di laksanakan pada bulan Oktober sampai dengan November 2020. Penelitian ini merupakan penelitian kuantitatif dengan pendekatan deskriptif untuk melihat hubungan kausal. Penelitian ini menggunakan data primer dan sekunder. Data Primer merupakan hasil pengambilan data langsung dari narasumber dengan adanya pembagian kuesioner kepada 100 responden yang minimal telah melakukan dua kali pembelian di Gramedia Manado. Data Sekunder didapatkan dari sumber yang sudah ada (buku, jurnal, websaite dan sebagainya) untuk acuan pembuatan laporan. Analisis data menggunakan analisis regresi berganda. Hasil Penelitian menunjukkan bahwa bauran pemasaran secara simultan berpengaruh dan signifikan terhadap keputusan pembelian di Gramedia Manado. ${ }^{*}$ eprm*
\end{abstract}

Kata Kunci : bauran pemasaran, keputusan pembelian, konsumen 


\section{PENDAHULUAN}

\section{Latar Belakang}

Munculnya berbagai macam persaingan di dunia bisnis mendorong para pelaku usaha untuk melakukan strategi pemasaran yang baik untuk dapat menjamin kelangsungan hidup suatu perusahaan. Strategi pemasaran sangat penting dalam keberlangsungan kegiatan pemasaran dan terutama dalam menjalankan suatu kegiatan bisnis yang merupakan sebuah sarana untuk mencapai suatu tujuan dalam kegiatan usaha.

Semakin ketatnya persaingan antar perusahaan yang terlibat dalam pemenuhan kebutuhan dan keinginan konsumen, menyebabkan perusahaan harus menempatkan orientasi pada kepuasan konsumen agar nantinya konsumen tersebut tidak akan berpindah ke perusahaan lain yang menjual produk atau jasa yang serupa. Untuk mewujudkan semuanya itu, peran manajemen pemasaran sangat diperlukan.

Manajemen pemasaran diperlukan agar kinerja perusahaan dapat berjalan dengan baik, juga untuk menilai dan meningkatkan pendapatan perusahaan, efisiensi perusahaan dan keefektifan kinerja. Aktivitas pemasaran yang terstruktur dalam menyampaikan informasi pemasaran secara luas, berorientasi dalam pengenalan suatu produk barang dan jasa, yang nantinya di harapkan dapat menciptakan kesan pribadi dan minat beli terhadap produk tersebut. Unsur strategi pemasaran yang sering di kenal yaitu strategi bauran pemasaran (Marketing mix) yang biasa dikenal dengan 7P terdiri dari Product (Produk), Price (Harga), Promotion (Promosi), Place (Tempat atau Saluran Distribusi), People (orang), process (Proses), dan Physical evidence (Sarana Fisik) sering di terapkan dalam perusahaan.

Memilih produk secara bebas dengan berbagai macam pilihan produk pengganti serta berbagai macam merek yang beragam merupakan impian konsumen dalam memilih pasar. Apabila konsumen merasa bahwa produk tersebut bisa memenuhi/ mencukupi keinginan dan kebutuhannya maka produk yang ditawarkan itu akan dibelinya. Setelah mempertimbangkan produk, konsumen akan memilih harga yang sesuai dengan kemampuannya yang telah di tetapkan pedagang atau perusahaan tempatnya membeli.
Harga memiliki peran yang sangat penting dalam pemasaran. Minat konsumen dan keterjangkauan pasar terhadap suatu produk akan menurun jika harga yang ditawarkan terlalu mahal. Harga adalah salah satu penentu pemilihan produk yang nantinya akan berpengaruh terhadap keputusan pembelian. Selain penetapan harga, manajer pemasaran juga di tuntut untuk dapat memperkenalkan produk mereka dengan melakukan promosi. Promosi yang baik akan mendatangkan banyak pelanggan yang merasa tertarik terhadap suatu produk yang dipromosikan. Tidak hanya itu lokasi juga menjadi pertimbangan konsumen dalam melakukan pembelian.

Tempat/ lokasi yang strategis dan mudah terjangkau, serta akses transportasi yang mudah dapat menjadi acuan buat perusahaan untuk meningkatkan volume penjualan mereka. Dengan demikian setelah penetapan produk, harga, promosi dan lokasi tadi telah terlaksana, untuk meraih minat beli perusahaan juga harus dapat menciptakan suasana yang nyaman dan menyenangkan baik dari segi fisik bangunan, perlengkapan yang ada dalam toko tersebut, logo perusahaan yang menarik serta pelayanan yang baik dari para karyawan dapat mengantar konsumen kepada keputusan pembelian. Karena apabila semua unsur dalam bauran pemasaran itu tidak terlaksanakan dengan baik dan perusahaan tidak memiliki manajemen yang baik dan hanya mengikuti trend saja maka perusahaan akan mengalami kerugian.

Gramedia Manado adalah salah satu toko buku yang merupakan perusahaan ritel di kota manado yang menjual beraneka ragam produk dan menerapkan strategi bauran pemasaran tersebut dalam memasarkan produknya. Observasi awal peneliti di toko buku Gramedia diperoleh keluhan dari konsumen bahwa ketersediaan buku masih kurang terbaharui karena ada beberapa buku yang sudah terbit dan di jual di toko buku lainnya belum tersedia di Gramedia Manado, demikian juga ada yang menyatakan bahwa pegawai di bagian penjualan kurang tanggap dalam memberikan pelayanan pada saat konsumen mencari barang yang mereka butuhkan. Padahal pegawai di bagian penjualan merupakan ujung tombak dalam upaya peningkatan profit sehingga perusahaan akan mengalami kerugian apabila tidak memperhatikan masalah-masalah tersebut dan akibatnya pendapatan perusahaan akan menurun kemudian perusahaan akan kehilangan pelanggan/ konsumen dan mengalami kerugian. 
Pada saat observasi juga peneliti menemukan bahwa penerapan strategi bauran pemasaran (Marketing Mix) di lakukan Gramedia diharapkan dapat meningkatkan volume penjualan tetapi malah menunjukkan tingkat volume penjualan yang tidak tetap selama 3 tahun terakhir.

\section{Bauran Pemasaran}

Strategi dalam pemasaran yang biasa disebut dengan bauran pemasaran (Marketing Mix), sangat berperan dalam mempengaruhi konsumen untuk membeli produk atau jasa yang ditawarkan. Menurut Kotler (2012), bauran pemasaran ditentukan dengan kegiatan pemasaran yang sedang berlangsung. Bauran pemasaran merupakan seperangkat alat pemasaran yang di manfaatkan untuk dapat mencapai pasar sasaran dan tujuan perusahaan secara materus-menerus.

\section{Perilaku Konsumen}

Perilaku konsumen yaitu tanggapan atau reaksi yang ditunjukan individu pada saat menyukai sesuatu. Dalam pemenuhan kebutuhan konsumen kerap kali harus membeli apa yang mereka butuhkan untuk itu pemasar perlu untuk memahami tingkah laku konsumen. Menurut Sunarto (2018), salah satu faktor yang penting untuk mengetahui perilaku konsumen adalah dengan mempelajari faktor psikologis dari konsumen, yaitu sikap konsumen, dengan demikian apabila sikap konsumen dapat didefenisikan dengan baik dan selanjutnya mengetahui minatnya maka perilaku konsumen akan dapat dipredikasi.

\section{Rumusan Masalah}

Berdasarkan uraian latar belakang diatas maka dapat dirumuskan masalah yang akan di teliti yaitu :

1. Apakah bauran pemasaran (produk, harga, promosi, tempat/ saluran distribusi, orang, proses dan sarana fisik) berpengaruh secara simultan terhadap keputusan pembelian di Gramedia Manado?

2. Apakah produk berpengaruh terhadap keputusan pembelian di Gramedia Manado?

3. Apakah harga berpengaruh terhadap keputusan pembelian di Gramedia Manado?

4. Apakah promosi berpengaruh terhadap keputusan pembelian di Gramedia Manado?

5. Apakah tempat/ saluran distribusi berpengaruh terhadap keputusan pembelian di Gramedia Manado?
6. Apakah orang berpengaruh terhadap keputusan pembelian di Gramedia Manado?

7. Apakah proses berpengaruh terhadap keputusan pembelian di Gramedia Manado?

8. Apakah sarana fisik berpengaruh terhadap keputusan pembelian di Gramedia Manado?

\section{Tujuan Penelitian}

Adapun tujuan peneitian sebagai berikut:

1. Untuk mengetahui apakah bauran pemasaran (produk, harga, promosi, tempat/ saluran distribusi, orang, proses dan sarana fisik) berpengaruh secara simultan terhadap keputusan pembelian di Gramedia Manado.

2. Untuk mengetahui apakah produk berpengaruh terhadap keputusan pembelian di Gramedia Manado.

3. Untuk mengetahui apakah harga berpengaruh terhadap keputusan pembelian di Gramedia Manado.

4. Untuk mengetahui apakah promosi berpengaruh terhadap keputusan pembelian di Gramedia Manado.

5. Untuk mengetahui apakah tempat/ saluran distribusi berpengaruh terhadap keputusan pembelian di Gramedia Manado.

6. Untuk mengetahui apakah orang berpengaruh terhadap keputusan pembelian di Gramedia Manado.

7. Untuk mengetahui apakah proses berpengaruh terhadap keputusan pembelian di Gramedia Manado.

8. Untuk mengetahui apakah saran fisik berpengaruh terhadap keputusan pembelian di Gramedia Manado.

\section{Manfaat Penelitian}

Adapun manfaat dari penelitian ini yaitu :

1. Secara Teoritis : diharapkan hasil penelitian ini dapat menjadi bahan perbandingan untuk penelitian selanjutnya terkait Bauran Pemasaran (marketing mix) suatu perusahaan dan juga penelitian ini menambah wawasan peneliti tentang cara penerapan marketing mix dan faktor-faktor apa saja yang mempengaruhi keputusan pembelian.

2. Secara praktis: Penelitian ini diharapkan dapat bermanfaat sebagai bahan evaluasi dan dapat memberikan sumbangan pemikiran bagi pihak Gramedia maupun perusahaan ritel lainnya dalam menerap bauran pemasaran (marketing mix) agar lebih baik lagi dalam menarik konsumen. 


\section{METODE PENELITIAN}

Tempat dan Waktu Penelitian

Penelitian ini dilaksanakan di toko buku Gramedia, Jl. Sam Ratulangi No. 45, Wenang Selatan, kota Manado. Penelitian ini di laksanakan pada bulan oktober sampai dengan November 2020.

\section{Jenis Penelitian}

Penelitian ini merupakan penelitian kuantitatif dengan pendekatan deskriptif untuk melihat hubungan kausal.

\section{Populasi}

\section{Populasi dan Sampel}

Menurut Sugiyono (2017), populasi adalah wilayah generalisasi yang terdiri atas; obyek/subyek yang mempunyai kualitas dan karakteristik tertentu yang ditetapkan oleh peneliti untuk dipelajari dan kemudian ditarik kesimpulannya. Populasi dalam penelitian ini adalah konsumen yang telah melakukan minimal dua kali pembelian di Gramedia Manado yang jumlahnya tidak di ketahui dan dapat dikatakan dalam kategori tak terhingga.

\section{Sampel}

Menurut Sugiyono (2017), sampel adalah bagian dari jumlah dan karakteristik yang dimiliki oleh populasi tersebut. Teknik pengambilan sampel yang digunakan dalam penelitian ini adalah mengunakan nonprobability sampling yaitu dengan teknik purposive sampling. Berdasarkan Sugiyono (2017), Sugiyono berpendapat bahwa Sampling non-probabilitas merupakan suatu cara dalam mengambil sampel dimana setiap unsur atau anggota populasi tidak memiliki kesempatan yang sama untuk terpilih. Sugiyono (2017), purposive sampling merupakan cara pengambilan sampel dengan kriteria tertentu. Untuk mendapatkan sampel sesuai dengan kriteria tertentu maka dilakukanlah penentuan sampel dengan purposive sampling ini.

Kriteria sampel harus ditentukan agar tidak terjadi kesalahan dalam pengambilan sampel penelitian yang bisa berdampak terhadap hasil penelitian. Sampel dalam penelitian ini yaitu konsumen yang telah melakukan minimal dua kali pembelian di Gramedia Manado. Untuk menentukan sampel yang tidak diketahui jumlah populasinya, menurut Roscoe (1975) dalam Uma Sekaran (200`6), memberikan acuan umum untuk menentukan ukuran sampel yaitu ukuran sampel lebih dari 30 dan kurang dari 500 adalah tepat untuk kebanyakan penelitian. Berdasarkan rumus dan pernyataan di atas dan karena banyaknya keterbatasan dalam melakukan penelitian ini, maka sampel yang di gunakan dalam penelitian ini sebanyak 100 responden.

\section{Teknik dan metode Pengumpulan data}

Dalam pengumpulan data peneliti menggunakan kuesioner, yang akan dibagikan kepada konsumen yang minimal telah melakukan pembelian 2 kali. Dari jawaban konsumen tersebut peneliti dapat menyimpulkan, menjawab dan mengkaji apa yang menjadi tujuan dibuatnya penelitian ini. Terdapat dua data dalam penelitian ini yaitu: sumber data primer atau utama dan sumber data sekunder.

a. Data Primer atau data utama merupakan hasil pengambilan data langsung dari narasumber dengan adanya pembagian kuesioner kepada responden yang minimal telah melakukan dua kali pembelian di Gramedia Manado.

b. Data Sekunder atau data pendukung merupakan data penelitian yang didapatkan dari sumber yang sudah ada (buku, jurnal, website dan sebagainya) untuk acuan pembuatan laporan.

\section{Instrumen dan skala Penelitian}

Data diperoleh dengan menggunakan angket/ kuisioner. Jawaban konsumen dinilai dengan menggunakan skala Likert. Skor untuk skala likert berniai 1-5, dimana jawaban 5 yang diberikan konsumen merupakan jawaban terbesar dan 1 jawaban terkecil dalam skala Likert. Berikut format jawaban penilaian: skor 1 . sangat tidak setuju, skor 2. tidak setuju, Skor 3. Netral, Skor 4. Setuju, Skor 5. sangat setuju. Di dalam penelitian ini, pengujiannya dilakukan terhadap 100 responden yang dijadikan sampel dengan tingkat signifikansi 5\% dengan bantuan aplikasi komputer yaitu SPSS untuk menguji validitas dan realibilitas kuisioner.

\section{Identitas Variabel Penelitian}

Penentuan variabel berdasarkan pengaruh bauran pemasaran (marketing mix) terhadap keputusan pembelian di Gramedia Manado, yaitu:

a. Independent variable (variabel bebas) dalam penelitian ini yaitu Bauran pemasaran (X) pada toko buku Gramedia.

b. Dependen variabel (variabel terikat) yaitu keputusan pembelian (Y) pada toko buku Gramedia Manado. 


\section{Teknik Analisis Data}

Teknik analisis data yang dilakukan dalam penelitian ini adalah sebagai berikut:

1. Analisis regresi berganda

Analisis regresi linear berganda digunakan penelitian ini untuk mengukur pengaruh satu atau beberapa variabel independen terhadap satu buah variabel dependen. Analisis regresi berganda akan dilakukan apabila jumlah dari variabel independennya minimal 2. Persamaan regresi yang digunakan penelitian ini adalah sebagai berikut:

$\mathrm{Y}=\alpha+\beta 1 \mathrm{X} 1+\beta 2 \mathrm{X} 2+\beta 3 \mathrm{X} 3+\beta 4 \mathrm{X} 4+\beta 5 \mathrm{X} 5$
$+\beta 6 \mathrm{X} 6+\beta 7 \mathrm{X} 7+\mathrm{e}$
Keterangan :
$\mathrm{Y}=$ Keputusan Pembelian
$\alpha=$ Nilai konstanta
$\mathrm{X} 1=$ Produk
$\mathrm{X} 2=$ Harga
$\mathrm{X} 3=$ Distribusi
$\mathrm{X} 4=$ Promosi
$\mathrm{X} 5=$ Orang
$\mathrm{X} 6=$ Proses
$\mathrm{X} 7=$ Sarana Fisik
$\mathrm{e}=$ Error

2. Uji asumsi klasik

\section{a) Uji Normalitas}

Uji normalitas digunakan untuk menguji apakah distribusi variabel terkait untuk setiap variabel bebas tertentu berdistribusi normal atau tidak dalam model regresi linear, asumsi ini ditunjukkan oleh nilai eror yang berdistribusi normal. Uji normalitas data dilakukan dengan menggunakan Test Normality KolmogorovSmirnov :

1) Jika probabilitas > 0,05 maka distribusi dari model regresi adalah normal.

2) Jika probabilitas < 0,05 maka distribusi dari model regresi adalah tidak normal.

b) Uji Multikolinearitas

Uji ini digunakan untuk melihat interkorelasi antar variabel bebas, dengan melihat nilai VIF (Variance Inflating Factor) dan toleransi. Terjadi multikolinieritas jika nilai VIF lebih besar dari 5 dan non multikolinieritas jika lebih kecil dari 5.

c) Uji Heteroskedastisidas

Uji ini pada dasarnya digunakan untuk menguji ketidaksamaan variance akan model regresi yang digunakan. Dasar pengambilan keputusan pada uji heteroskedastisitas yakni: Jika nilai signifikansi $>\mathrm{a}=0.05$, kesimpulannya adalah tidak terjadi heteroskedastisitas dan sebaliknya.

\section{HASIL DAN PEMBAHASAN}

\section{Deskripsi Objek Penelitian}

Toko buku Gramedia yang dikenal dengan sebutan PT. Gramedia Asri Media yang merupakan "anak perusahaan kelompok kompas Gramedia", yang berdiri pada tanggal 2 Februari 1970. Pada awalnya toko buku Gramedia ini berukuran $25 \mathrm{~m}^{2}$, yang terletak di daerah Gajah Mada, Jakarta Pusat. Pendirinya yaitu Jacob Oetama dan Petrus Kanisius Ojong yang merupakan 2 sahabat yang memiliki visi yang sama untuk mengembangkan dunia pendidikan dan kesejahteraan untuk menjamin masa depan masyarakat di Indonesia. Seiring berkembangnya waktu dengan melihat peluang pasar, toko buku Gramedia mengembangkan produknya. Toko buku gramedia kini tidak hanya menjual buku saja tetapi sudah menambah variasi pada produknya seperti: perlengkapan alat tulis menulis, alat olahraga, aksesoris, kamera, kamus elektronik, alat musik dan sebagainya. Toko buku Gremedia berperan sebagai penerbit baik dari luar maupun dalam negeri. Pemasok dalam negeri seperti: Gramedia pustaka utama, Bhuana ilmu populer, Gramedia Widya sarana, Gramedia majalah dan Elex media komputindo. Pemasok luar negeri: McGraw Hill, Prentice Hall, dan Addison Wesley.

Toko buku Gramedia Sam Ratulangi merupakan toko buku Gramedia yang berada di Manado. Toko buku Gramedia Sam Ratulangi Manado mulai beroperasi sejak 26 Februari 2000 dengan luas area jual $1600 \mathrm{~m} 2$. Dengan area jual yang sangat luas, Gramedia SAMRAT Manado memiliki 24 counter yang menjual barang antara lain: tas, stationery, computer suplies, dll.

\section{Visi dan Misi toko buku Gramedia}

Menjadi perusahaan jaringan ritel dan penerbitan terbesar, tersebar, dan terpadu di Asia Tenggara, melalui penyediaan produk berorientasi pasar, layanan unggul, inovatif dan perilaku bisnis yang beretika.

\section{Umur}

\section{Karakteristik Responden}

Distribusi Presentase responden

berdasarkan umur dapat di lihat pada tabel di bawah ini : 
Tabel 1. Umur Responden

\begin{tabular}{|c|c|c|c|c|c|}
\hline & & Frequency & Percent & $\begin{array}{c}\text { Valid } \\
\text { Percent }\end{array}$ & $\begin{array}{c}\text { Cumulative } \\
\text { Percent }\end{array}$ \\
\hline \multirow{6}{*}{ Valid } & $\begin{array}{l}>45 \\
\text { tahun }\end{array}$ & 12 & 12.0 & 12.0 & 12.0 \\
\hline & $\begin{array}{l}15-20 \\
\text { tahun }\end{array}$ & 35 & 35.0 & 35.0 & 47.0 \\
\hline & $\begin{array}{l}21-25 \\
\text { tahun }\end{array}$ & 35 & 35.0 & 35.0 & 82.0 \\
\hline & $\begin{array}{l}26-30 \\
\text { tahun }\end{array}$ & 11 & 11.0 & 11.0 & 93.0 \\
\hline & $\begin{array}{l}31-45 \\
\text { tahun }\end{array}$ & 7 & 7.0 & 7.0 & 100.0 \\
\hline & Total & 100 & 100.0 & 100.0 & \\
\hline
\end{tabular}

Tabel 1. Menunjukkan data distribusi presentase keseluruhan umur responden. Untuk umur 15-20 tahun berjumlah 35\%, umur 21-25 tahun berjumlah 35\%, umur 26-30 tahun berjumlah $11 \%$, umur 31-45 tahun berjumlah $7 \%$, dan umur $>45$ tahun berjumlah $12 \%$.

\section{Jenis Kelamin}

Distribusi presentase untuk jenis kelamin responden dapat di lihat pada tabel di bawah ini :

\begin{tabular}{ccccc}
\hline Tabel 2. Jenis Kelamin Responden & & \\
\hline & $\begin{array}{c}\text { Frequenc } \\
\mathbf{y}\end{array}$ & & $\begin{array}{c}\text { Valid } \\
\text { Percent }\end{array}$ & $\begin{array}{c}\text { Cumulativ } \\
\text { e Percent }\end{array}$ \\
\hline Pria & 42 & 42.0 & 42.0 & 42.0 \\
Valid Wanita & 58 & 58.0 & 58.0 & 100.0 \\
Total & $\mathbf{1 0 0}$ & $\mathbf{1 0 0 . 0}$ & $\mathbf{1 0 0 . 0}$ & \\
\hline
\end{tabular}

Sumber : Hasil olah data Primer 2020

Tabel 2. Menunjukkan bahwa dari semua responden tedapat $42 \%$ responden yang berjenis kelamin Pria, dan responden yang berjenis kelamin wanita berjumlah $58 \%$. Dari data tersebut dapat disimpulkan bahwa responden berjenis kelamin wanita lebih banyak dikarenakan wanita lebih banyak mengurus keperluan rumah tangga, sekolah anak dan sebagainya.

\section{Pendidikan}

Distribusi presentase pendidikan responden dapat di lihat pada tabel di bawah ini:

\begin{tabular}{clcccc} 
Tabel 3. Pendidikan Responden & & & \\
\hline & Frequency & Percent & $\begin{array}{c}\text { Valid } \\
\text { Percent }\end{array}$ & $\begin{array}{c}\text { Cumulativ } \\
\text { e Percent }\end{array}$ \\
\hline Diploma & 3 & 3.0 & 3.0 & 3.0 \\
Lainnya... & 20 & 20.0 & 20.0 & 23.0 \\
Valid & 10 & 10.0 & 10.0 & 33.0 \\
& Pascasarjana & 36 & 36.0 & 36.0 & 69.0 \\
& Sarjana & 31 & 31.0 & 31.0 & 100.0 \\
SMA & 31 & $\mathbf{1 0 0}$ & $\mathbf{1 0 0 . 0}$ & $\mathbf{1 0 0 . 0}$ & \\
\hline
\end{tabular}

Sumber : Hasil olah data Primer 2020
Tabel 3. Menunjukkan data pendidikan dari keseluruhan responden. Untuk tingkat pendidikan SMA berjumlah $31 \%$, tingkat pendidikan diploma sebanyak $3 \%$, tingkat pendidikan sarjana berjumlah $36 \%$, tingkat pendidikan pacasarjana berjumlah $10 \%$ dan tingkat pendidikan lainnya berjumlah $20 \%$.

\section{Pekerjaan}

Distribusi presentase pekerjaan responden dapat dilihat pada tabel di bawah ini:

\begin{tabular}{|c|c|c|c|c|c|}
\hline & & Frequency & Percent & $\begin{array}{c}\text { Valid } \\
\text { Percent }\end{array}$ & $\begin{array}{c}\text { Cumulative } \\
\text { Percent }\end{array}$ \\
\hline \multirow{6}{*}{ Valid } & Lainnya... & 23 & 23.0 & 23.0 & 23.0 \\
\hline & Mahasiswa & 46 & 46.0 & 46.0 & 69.0 \\
\hline & $\begin{array}{l}\mathrm{PNS} / \mathrm{TNI} / \mathrm{POL} \\
\mathrm{RI}\end{array}$ & 13 & 13.0 & 13.0 & 82.0 \\
\hline & Siswa & 5 & 5.0 & 5.0 & 87.0 \\
\hline & Wiraswasta & 13 & 13.0 & 13.0 & 100.0 \\
\hline & Total & 100 & 100.0 & 100.0 & \\
\hline
\end{tabular}

Sumber : Hasil olah data Primer 2020

Tabel 4. Menunjukkan data keseluruhan pekerjaan responden. Pekerjaan sebagai siswa berjumlah 5\%, pekerjaan sebagai mahasiswa berjumlah $46 \%$, pekerjaan sebagai PNS/TNI/POLRI berjumlah $13 \%$, pekerjaan sebagai wiraswasta berjumlah $13 \%$ dan $23 \%$ pekerjaan lainnya.

\section{Penghasilan}

Distribusi presentase penghasilan responden/ bulan dapat di lihat pada tabel di bawah ini :

\begin{tabular}{lccccc}
\multicolumn{1}{l}{ Tabel 5. Penghasilan Responden } \\
\hline & Frequency & Percent & $\begin{array}{c}\text { Valid } \\
\text { Percent }\end{array}$ & $\begin{array}{c}\text { Cumulative } \\
\text { Percent }\end{array}$ \\
\hline \multirow{4}{*}{ Valid } & $<1$ juta & 40 & 40.0 & 40.0 & 40.0 \\
& $>5$ juta & 17 & 17.0 & 17.0 & 57.0 \\
& $1-2$ juta & 19 & 19.0 & 19.0 & 76.0 \\
& $2-3$ juta & 10 & 10.0 & 10.0 & 86.0 \\
& $3-5$ juta & 14 & 14.0 & 14.0 & 100.0 \\
& Total & $\mathbf{1 0 0}$ & $\mathbf{1 0 0 . 0}$ & $\mathbf{1 0 0 . 0}$ & \\
\hline
\end{tabular}

Sumber : Hasil olah data Primer 2020

Tabel 5. Menunjukkan data keseluruhan dari penghasilan responden. Penghasilan responden $<1$ juta berjumlah $40 \%$, penghasilan responden 1-2 juta berjumlah 19\%, penghasilan responden 2-3 juta berjumlah $10 \%$, penghasilan responden 3-5 juta berjumlah 14\%, dan penghasilan responden $>5$ juta berjumlah $17 \%$.

\section{Pengeluaran}

Distribusi presentase pengeluaran responden/ bulan dapat di lihat pada tabel di bawah ini : 
Tabel 6. Pengeluaran Responden

\begin{tabular}{cccccc}
\hline & & Frequency & Percent & $\begin{array}{c}\text { Valid } \\
\text { Percent }\end{array}$ & $\begin{array}{c}\text { Cumulative } \\
\text { Percent }\end{array}$ \\
\hline \multirow{6}{*}{ Valid } & $<1$ juta & 43 & 43.0 & 43.0 & 53.0 \\
& $<5$ juta & 10 & 10.0 & 10.0 & 10.0 \\
& $1-2$ juta & 20 & 20.0 & 20.0 & 73.0 \\
& $2-3$ juta & 13 & 13.0 & 13.0 & 86.0 \\
& 3-5 juta & 14 & 14.0 & 14.0 & 100.0 \\
& Total & $\mathbf{1 0 0}$ & $\mathbf{1 0 0 . 0}$ & $\mathbf{1 0 0 . 0}$ & \\
\hline
\end{tabular}

Sumber : Hasil olah data Primer 2020

Tabel 6. Diatas menunjukkan pengeluaran responden/ bulan yaitu untuk pengeluaran $<1$ juta berjumlah $53 \%$, pengeluaran 1-2 juta berjumlah $20 \%$, pengeluaran 2-3 juta berjumlah $13 \%$, pengeluaran 3-5 juta berjumlah $14 \%$, selanjutnya yang pengeluaran $<5$ juta/ bulan berjumlah $10 \%$.

\section{Konsumen yang membeli produk Gramedia}

Distibusi presentase responden yang membeli produk di Gramedia dapat di lihat pada tabel di bawah ini:

Tabel 7. Apakah anda pernah membeli produk di Gramedia Manado? (Jika tidak maka tidak dapat mengisi kuisioner ini selanjutnya)

\begin{tabular}{|c|c|c|c|c|}
\hline & $\begin{array}{l}\text { Frequenc } \\
\mathbf{y}\end{array}$ & rcent & $\begin{array}{l}\text { Valid } \\
\text { Percent }\end{array}$ & $\begin{array}{l}\text { Cumulative } \\
\text { Percent }\end{array}$ \\
\hline Valid Ya & 100 & 100.0 & 100.0 & 100. \\
\hline
\end{tabular}

Sumber : Hasil olah data Primer 2020

Tabel 7. Menunjukkan bahwa responden yang di gunakan dala penelitian ini yaitu orang-orang yang telah atau sudah pernah melakukan pembelian di gramedia manado dengan presentase $100 \%$.

\section{Rerata Pembelian/ bulan}

Distribusi presentase rerata pembelian responden/ bulan dapat di lihat pada tabel di bawah ini:

Tabel 8. Rata-rata pembelian dalam satu bulan?

\begin{tabular}{|c|c|c|c|c|c|}
\hline & & Frequency & Percent & $\begin{array}{l}\text { Valid } \\
\text { Percent }\end{array}$ & $\begin{array}{l}\text { Cumulative } \\
\text { Percent }\end{array}$ \\
\hline \multirow{6}{*}{ Valid } & $>7$ kali & 2 & 2.0 & 2.0 & 2.0 \\
\hline & 6-7 kali & 2 & 2.0 & 2.0 & 2.0 \\
\hline & 1 kali & 28 & 28.0 & 28.0 & 28.0 \\
\hline & 2-3 kali & 56 & 56.0 & 56.0 & 88.0 \\
\hline & 4-5 kali & 12 & 12.0 & 12.0 & 100.0 \\
\hline & Total & 100 & 100.0 & 100.0 & \\
\hline
\end{tabular}

Sumber : Hasil olah data Primer 2020

Tabel 8. Menunjukkan presentase rerata pembelian responden/ bulan dimana untuk rerata 1 kali/ bulan berjumlah $28 \%$, rerata $2-3 \mathrm{kali} /$ bulan berjumlah $56 \%$, rerata pembelian $4-5 \mathrm{kali} /$ bulan berjumlah $12 \%$ dan selanjutnya rerata pembelian 6-
7 kali/ bulan berjumlah $2 \%$ juga untuk $>7$ kali pembelian/ bulan berjumlah $2 \%$.

\section{Uji Instrumen Penelitian}

a. Uji Validitas

Instrumen penelitian dapat dikatakan valid dengan melihat derajat ketetapan antara data yang terjadi pada obyek penelitian dengan data yang dapat dilaporkan oleh penelitian (Sugiyono, 2017). "Untuk mengetahui apakah instrumen tersebut valid yaitu dengan membandingkan indeks korelasi product moment pearson dengan level signifikansi 5\%". Bila nilai signifikan lebih kecil dari 0,05 maka dinyatakan valid dan jika lebih besar dari 0,05 maka dinyatakan tidak valid. Berikut dapat kita lihat pengujian valititas instrumen yang ditunjukan pada tabel di bawah ini:

\begin{tabular}{|c|c|c|c|c|c|}
\hline Variabel & Item & $\begin{array}{c}\mathbf{R} \\
\text { Hitung }\end{array}$ & $\begin{array}{c}\mathbf{R} \\
\text { Tabel }\end{array}$ & sig & Keterangan \\
\hline \multirow{3}{*}{ Produk (X1) } & $\mathrm{X} 1.1$ & 0.543 & 0.163 & 0,000 & VALID \\
\hline & $\mathrm{X} 2.2$ & 0.752 & 0.163 & 0,000 & VALID \\
\hline & X3.3 & 0.656 & 0.163 & 0,000 & VALID \\
\hline \multirow[t]{3}{*}{ Harga (X2) } & $\mathrm{X} 2.1$ & 0.763 & 0.163 & 0,000 & VALID \\
\hline & $\mathrm{X} 2.2$ & 0.707 & 0.163 & 0,000 & VALID \\
\hline & $\mathrm{X} 2.3$ & 0.718 & 0.163 & 0,000 & VALID \\
\hline \multirow{3}{*}{$\begin{array}{l}\text { Lokasi/Distribusi } \\
\text { (X3) }\end{array}$} & $\mathrm{X} 3.1$ & 0.510 & 0.163 & 0,000 & VALID \\
\hline & $\mathrm{X} 3.2$ & 0.560 & 0.163 & 0,000 & VALID \\
\hline & $\mathrm{X} 3.3$ & 0.569 & 0.163 & 0,000 & VALID \\
\hline \multirow[t]{3}{*}{ Promosi (X4) } & X4.1 & 0.821 & 0.163 & 0,000 & VALID \\
\hline & $\mathrm{X} 4.2$ & 0.632 & 0.163 & 0,000 & VALID \\
\hline & X4.3 & 0.781 & 0.163 & 0,000 & VALID \\
\hline \multirow[t]{2}{*}{ Orang (X5) } & $\mathrm{X} 5.1$ & 0.517 & 0.163 & 0,000 & VALID \\
\hline & $\mathrm{X} 5.2$ & 0.643 & 0.163 & 0,000 & VALID \\
\hline \multirow[t]{2}{*}{ Proses (X6) } & X6.1 & 0.731 & 0.163 & 0,000 & VALID \\
\hline & $\mathrm{X} 6.2$ & 0.698 & 0.163 & 0,000 & VALID \\
\hline \multirow[t]{3}{*}{ Sarana Fisik (X7) } & $\mathrm{X} 7.1$ & 0.662 & 0.163 & 0,000 & VALID \\
\hline & $\mathrm{X} 7.2$ & 0.631 & 0.163 & 0,000 & VALID \\
\hline & $\mathrm{X} 7.3$ & 0.636 & 0.163 & 0,000 & VALID \\
\hline \multirow{7}{*}{$\begin{array}{l}\text { Keputusan } \\
\text { Pembelian (Y) }\end{array}$} & Y1. 1 & 0.561 & 0.163 & 0,000 & VALID \\
\hline & Y1. 2 & 0.639 & 0.163 & 0,000 & VALID \\
\hline & Y1. 3 & 0.630 & 0.163 & 0,000 & VALID \\
\hline & Y1. 4 & 0.634 & 0.163 & 0,000 & VALID \\
\hline & Y1. 5 & 0.594 & 0.163 & 0,000 & VALID \\
\hline & Y1. 6 & 0.570 & 0.163 & 0,000 & VALID \\
\hline & Y1. 7 & 0.666 & 0.163 & 0,000 & VALID \\
\hline
\end{tabular}

Berdasarkan Tabel 9 di atas, dimana kuesioner disebarkan kepada 100 responden dapat dinyatakan valid. Hal ini dikarenakan nilai sigifikannya di bawah 0,05 dan nilai $r$ hitung lebih besar dari $r$ tabel. Sehingga seluruh pernyataan dalam kuesioner dapat di gunakan.

\section{b. Uji Reliabilitas}

Dari uji reliabilitas pada Tabel 10, dapat dilihat bahwa bauran pemasaran yang terdiri dari 7 variabel memiliki nilai Alpha's Cronbach $>0,6$. Jadi kesimpulannya untuk seluruh item pernyataan dinyatakan reliabel sehingga digunakan sebagai instrument penelitian. 
Tabel 10. Uji reliabilitas instrument

\begin{tabular}{lcc}
\hline \multicolumn{1}{c}{ Variabel } & $\begin{array}{c}\text { Alpha's } \\
\text { Cronbach }\end{array}$ & Keterangan \\
\hline Harga (X1) & 0.719 & Reliable \\
Produk (X2) & 0.779 & Reliable \\
Lokasi/Distribusi (X3) & 0.638 & Reliable \\
Promosi (X4) & 0.858 & Reliable \\
Orang (X5) & 0.533 & Reliable \\
Proses (X6) & 0.747 & Reliable \\
Sarana Fisik (X7) & 0.674 & Reliable \\
Keputusan Pembelian (Y) & 0.806 & Reliable \\
\hline
\end{tabular}

\section{Uji Normalitas}

Uji normalitas digunakan untuk menguji apakah sebaran/ distribusi data berdistribusi normal atau tidak dalam model regresi dan dilakukan untuk menilai sebaran data pada sebuah kelompok atau variabel. Uji normalitas dapat dilakukan dengan 3 cara yaitu : pendekatan Kolmogrov-Smirnov, pendekatan histogram, dan pendekatan grafik. Penelitian ini menggunakan pendekatan KolmogorovSmirnov Test dan pendekatan grafik yang dapat di lihat pada tabel dan gambar di bawah ini:

Tabel 11. Pendekatan Kolmogorov Smirnov - Test

\begin{tabular}{llr}
\hline \multicolumn{1}{l}{} & \multicolumn{2}{c}{$\begin{array}{c}\text { Unstandardized } \\
\text { Residual }\end{array}$} \\
\hline $\mathbf{N}$ & Mean & $\mathbf{1 0 0}$ \\
\hline Normal Parameters ${ }^{\mathrm{a}, \mathrm{b}}$ & Std. Deviation & .0000000 \\
& Absolute & .25032420 \\
Most Extreme Differences & Positive & .116 \\
& Negative & .107 \\
Kolmogorov-Smirnov Z & & -.116 \\
Asymp. Sig. (2-tailed) & & 1.161 \\
\hline a. Test distribution is Normal. & .135 \\
b. Calculated from data. & \\
\hline Sumber : Hasil olah data Primer 2020
\end{tabular}

Sumber : Hasil olah data Primer 2020

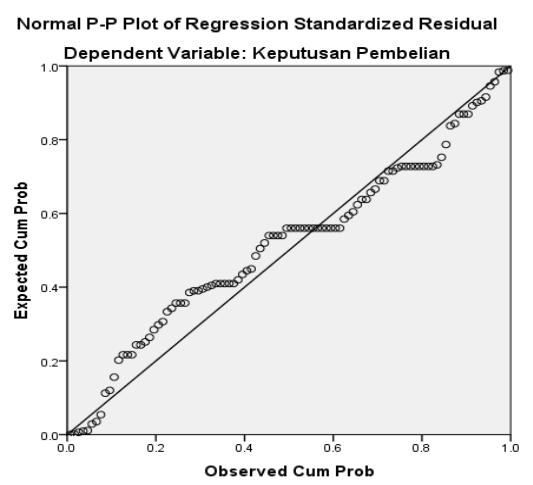

Gambar 1. Pendekatan Grafik

Sumber : Hasil olah data Primer 2020

Tabel 11. Pengujian normalitas menggunakan Kolmogorov-Smirnov Test terlihat bahwa nilai Asymp. Sig. adalah 0,135 > 0,05. Pada gambar scatterplot juga terlihat bahwa terdapat titik-titik yang mengikuti data di sepanjang garis diagonal. Dengan demikian, maka dapat di simpulkan bahwa distribusi data dari model regresi adalah normal.

\section{Uji Multikolinearitas}

Tabel 12. Uji multikolinearitas dapat dilakukan dengan melihat toleransi variable dan Variance Inflation Factor (VIF) dengan membandingkan VIF $<5$ dan tolerance $>0,05$ maka tidak terjadi multikolinearitas. Sehingga dapat disimpulkan bahwa regresi ini non multikolinearitas (tidak terjadi multikolinearitas).

\begin{tabular}{|c|c|c|c|c|c|c|c|}
\hline \multirow[t]{2}{*}{ Model } & \multicolumn{2}{|c|}{$\begin{array}{l}\text { Unstandardized } \\
\text { Coefficients }\end{array}$} & \multirow{2}{*}{$\begin{array}{l}\text { Standardized } \\
\text { Coefficients }\end{array}$} & \multirow[t]{2}{*}{$\mathbf{T}$} & \multirow[t]{2}{*}{ Sig. } & \multicolumn{2}{|l|}{$\begin{array}{l}\text { Collinearity } \\
\text { Statistics }\end{array}$} \\
\hline & B & $\begin{array}{c}\text { Std. } \\
\text { Error }\end{array}$ & & & & Tolerance & VIF \\
\hline (Constant) & 6.219 & 1.825 & & 3.408 & .001 & & \\
\hline Harga (X1) & -.411 & .210 & -.168 & -1.960 & .053 & .387 & 2.581 \\
\hline Produk (X2) & .489 & .162 & .288 & 3.027 & .003 & .312 & 3.205 \\
\hline $\begin{array}{l}\text { Lokasi/Distribusi } \\
\text { (X3) }\end{array}$ & .368 & .132 & .238 & 2.787 & .006 & .476 & 2.101 \\
\hline Promosi (X4) & .696 & .185 & .401 & 3.753 & .000 & .247 & 4.041 \\
\hline Orang (X5) & .391 & .105 & .298 & 3.715 & .000 & .540 & 1.853 \\
\hline Proses (X6) & .472 & .291 & .136 & 1.621 & .108 & .404 & 2.474 \\
\hline Sarana Fisik $(\mathrm{X} 7)$ & .628 & .180 & .278 & 3.483 & .001 & .444 & 2.254 \\
\hline
\end{tabular}

\section{Uji Heterokedastisitas}

Uji heteroskedastisitas digunakan untuk menguji apakah sebuah grup memiliki varians yang sama di antara grup tersebut. Jika varians tidak sama, dikatakan terjadi heteroskedastisitas. Untuk menguji heteroskedastisitas dapat dilakukan dengan model pendekatan grafik dan model pendekatan statistik.

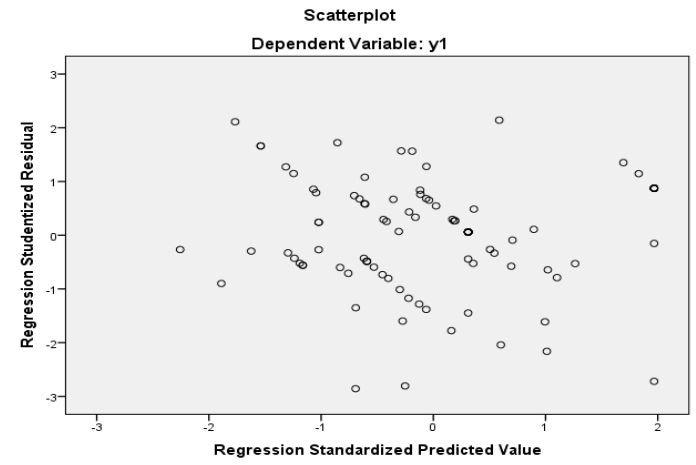

Gambar 2. Pendekatan Grafik Scatterplot Uji Heterokrdastisitas

Dari output scatterplot Gambar 2 di atas, titiktitik terlihat tersebar secara merata di atas dan di bawah angka 0 pada sumbu $Y$, dan tidak membentuk sebuah pola tertentu yang teratur. 
Sehingga dapat di simpulkan tidak terjadi heterokedastisitas.

\section{Uji Koefisien Korelasi}

Tabel 13. $\mathrm{R}=0,86$ dan nilai signifikannya adalah $0.05<0,000$. Jadi dapat di simpulkan bahwa korelasi variabel produk, harga, promosi, lokasi, orang, proses, dan sarana fisik terhadap keputusan pembelian sangat kuat yaitu 0,86 . Nilai Rsquare $=0,74$ yang berarti bauran pemasaran memberikan pengaruh sebanyak $74 \%$ terhadap keputusan pembelian dan 26 $\%$ dari variabel lain seperti merek, store associate, kualitas pelayanan, impulse buying, dan lain-lain yang tidak di teliti dalam penelitian ini.

Tabel 16. Model Summary

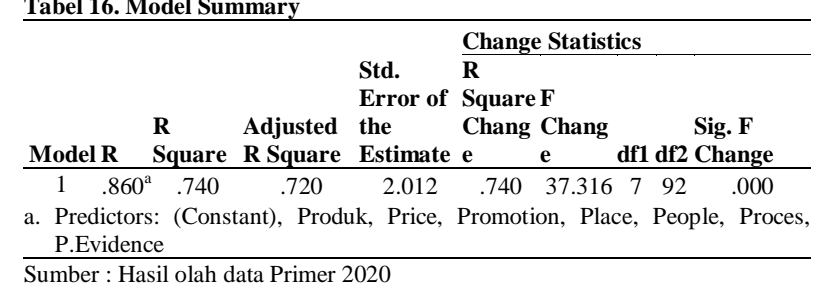

Analisis Regresi Berganda

a. Uji T (Uji Parsial)

Tabel 14. Coefficients ${ }^{\mathrm{a}}$

\begin{tabular}{|c|c|c|c|c|c|c|}
\hline \multirow{2}{*}{\multicolumn{2}{|c|}{ Model }} & \multicolumn{2}{|c|}{$\begin{array}{l}\text { Unstandardized } \\
\text { Coefficients }\end{array}$} & \multirow{2}{*}{$\begin{array}{c}\begin{array}{r}\text { Standardized } \\
\text { Coefficients }\end{array} \\
\text { Beta } \\
\end{array}$} & \multirow[b]{2}{*}{$\mathrm{t}$} & \multirow[b]{2}{*}{ Sig. } \\
\hline & & B & $\begin{array}{l}\text { Std. } \\
\text { Error }\end{array}$ & & & \\
\hline \multirow{8}{*}{1} & (Constant) & 6.219 & 1.825 & & 3.408 & .001 \\
\hline & Produk (X1) & -.411 & .210 & -.168 & -1.960 & .053 \\
\hline & Harga X2 & .489 & .162 & .288 & 3.027 & .003 \\
\hline & Lokasi/DistribusiX3 & .368 & .132 & .238 & 2.787 & .006 \\
\hline & Promosi (X4) & .696 & .185 & .401 & 3.753 & .000 \\
\hline & Orang (X5) & .391 & .105 & .298 & 3.715 & .000 \\
\hline & Proses (X6) & .472 & .291 & .136 & 1.621 & 108 \\
\hline & Sarana Fisik (X7) & .628 & .180 & .278 & 3.483 & .001 \\
\hline
\end{tabular}

Uji-t dilakukan untuk menguji secara parsial dan agar mengetahui bagaimana pengaruh dari masing-masing variabel bebasnya (produk $\mathrm{X} 1$, harga $\mathrm{X} 2$, lokasi atau distribusi $\mathrm{X} 3$, promosi $\mathrm{X} 4$, orang $\mathrm{X} 5$, proses $\mathrm{X} 6$, sarana fisik $\mathrm{X} 7$ ) terhadap variabel terikat (keputusan Pembelian). Model hipotesis yang digunakan dalam uji-t menurut Ghozali (2011) yaitu:

a. $\mathrm{H}_{0}$ diterima dan $\mathrm{Ha}$ ditolak jika angka probabilitas signifikan $>0,05$

b. $\mathrm{H}_{0}$ ditolak dan $\mathrm{Ha}$ diterima jika angka probabilitas signifikan $<0,05$

Dari model hipotesis di atas dapat disimpulkan bahwa :

1. Variabel Produk (X1) berpengaruh dan hampir signifikan terhadap keputusan pembelian pada toko buku Gramedia Manado, hal ini terlihat bahwa nilai signifikansinya $0,53>0,05$.

2. Variabel Harga (X2) berpengaruh secara positif dan signifikan terhadap keputusan pembelian pada Toko Buku Gramedia Manado, hal ini terlihat bahwa nilai signifikansinya $0,003<$ dari 0,05 .

3. Variabel Lokasi atau Distirbusi (X3) berpengaruh secara positif dan signifikan terhadap keputusan pembelian pada toko buku Gramedia Manado, hal ini terlihat bahwa nilai signifikansinya 0,006 $<0,05$.

4. Variabel Promosi (X4) berpengaruh secara positif dan signifikan terhadap keputusan pembelian pada toko buku Gramedia Manado, hal ini terlihat bahwa nilai signifikansinya $0,000<0,05$.

5. Variabel Orang (X5) berpengaruh secara positif dan signifikan terhadap keputusan pembelian pada Toko Buku Gramedia Manado, hal ini terlihat bahwa nilai signifikansinya $0,000<0,05$.

6. Variabel Proses (X6) berpengaruh secara positif dan tidak signifikan terhadap keputusan pembelian pada toko buku Gramedia Manado, hal ini terlihat bahwa nilai signifikansinya 0,108 $>0,05$.

7. Variabel Sarana Fisik (X7) berpengaruh secara positif dan signifikan terhadap keputusan pembelian pada toko buku Gramedia Manado, hal ini terlihat bahwa nilai signifikansinya 0,001 $<$ dari 0,05 .

Dari data di atas, dapat disimpulkan bahwa variabel yang berpengaruh positif dan signifikan terhadap keputusan pembelian adalah variabel harga (X2), Lokasi (X3), Promosi (X4), Orang (X5) dan Sarana Fisik (X7), dimana tingkat signifikansinya berada di bawah 0,05. Dan variabel yang berpengaruh tetapi tidak signifikan terhadap keputusan pembelian adalah variabel Produk (X1) dan Proses(X6).

\section{b. Uji F (Simultan)}

\section{Tabel 15. ANOVA ${ }^{\mathrm{a}}$}

\begin{tabular}{|c|c|c|c|c|c|c|}
\hline \multicolumn{2}{|c|}{ Model } & $\begin{array}{c}\text { Sum of } \\
\text { Squares }\end{array}$ & \multirow{2}{*}{$\begin{array}{l}\text { Df } \\
7\end{array}$} & \multirow{2}{*}{$\begin{array}{l}\text { Mean } \\
\text { Square } \\
151.003\end{array}$} & \multirow{2}{*}{$\frac{\mathbf{F}}{37.316}$} & \multirow{2}{*}{$\begin{array}{l}\text { Sig. } \\
.000^{\mathrm{b}}\end{array}$} \\
\hline 1 & Regressior & 1057.019 & & & & \\
\hline & Residual & 372.291 & 92 & 4.047 & & \\
\hline & Total & 1429.310 & 99 & & & \\
\hline
\end{tabular}

a. Dependent Variable: Keputusan Pembelian

b. Predictors: (Constant), Produk, Price, Promotion,

Place, People, Proces, P.Evidence,

Sumber : Hasil olah data Primer 2020

Uji F dilakukan untuk mengetahui apakah ada pengaruh secara bersama-sama antara variabel bauran pemasaran terhadap keputusan pembelian di 
Gramedia Manado. Model hipotesis yang di gunakan adalah:

a. $\mathrm{H}_{0}$ diterima bila $\mathrm{F}_{\text {hitung }}$ kurang dari atau sama dengan $\mathrm{F}_{\text {tabel }}$ pada tingkat signifikansi 5\%

b. $\mathrm{H}_{0}$ ditolak bila $\mathrm{F}_{\text {hitung }}$ lebih dari atau sama dengan $\mathrm{F}_{\text {tabel }}$ pada tingkat signifikansi $5 \%$

Hasil pengujian ANOVA dengan menggunakan uji-F pada table memperlihatkan nilai Fhitung:

$\mathrm{F}_{\text {hitung }}=37.316$ dan nilai $\mathrm{F}_{\text {tabel }} \mathrm{df} 1=7$, df2 $=$ $92=2.11$, jadi

$\mathrm{F}_{\text {hitung }}=37.316>\mathrm{F}_{\text {tabel }}=2.11$ dan untuk nilai probabilitas signifikannya yaitu 0.000 $<0,05$

Kesimpulannya $\mathrm{H}_{0}$ ditolak dan $\mathrm{Ha}$ diterima yang artinya secara bersama-sama (simultan) variabel bauran pemasaran berpengaruh dan signifikan terhadap keputusan pembelian di Gramedia Manado.

\section{KESIMPULAN DAN SARAN}

\section{Kesimpulan}

1. Bauran pemasaran secara simultan berpengaruh dan signifikan terhadap keputusan pembelian di Gramedia Manado.

2. Variabel produk berpengaruh dan hampir signifikan terhadap keputusan pembelian di Gramedia Manado.

3. Variabel harga berpengaruh secara positif dan signifikan terhadap keputusan pembelian di Gramedia Manado.

4. Variabel promosi berpengaruh secara positif dan signifikan terhadap keputusan pembelian di Gramedia Manado

5. Variabel tempat/ saluran distirbusi berpengaruh secara positif dan signifikan terhadap keputusan pembelian di Gramedia Manado.

6. Variabel orang berpengaruh secara positif dan signifikan terhadap keputusan pembelian di Gramedia Manado.

7. Variabel proses berpengaruh secara positif dan tidak signifikan terhadap keputusan pembelian di Gramedia Manado.

8. Variabel sarana fisik berpengaruh secara positif dan signifikan terhadap keputusan pembelian di Gramedia Manado.

\section{Saran}

Berdasarkan kesimpulan yang diuraikan, peneliti memberikan saran sebagai berikut:

1. Bagi Perusahaan

Bauran pemasaran memberikan pengaruh yang kuat terhadap keputusan pembelian di Gramedia Manado, dan ada variabel-variabel dalam bauran pemasaran yang tidak berpengaruh signifikan sehingga perusahaan harus lebih memperhatikan pengelolaan strategi bauran pemasarannya agar nantinya keputusan pembelian di Gramedia Manado lebih meningkat.

2. Bagi Penelti Selanjutnya

Ada beberapa faktor yang mempengaruhi keputusan pembelian yang tidak ditelti dalam penelitian ini seperti: merek, store associate, kualitas pelayanan, impulse buying, dan lainlai yang dapat di teliti oleh peneliti selanjutnya. Dan juga penelitian selanjutnya dapat melakukan penelitian promosi dan periklanan secara online pada masa pandemi Covid-19. Besarnya pengaruh bauran pemasaran hanyalah merupakan salah satu faktor yang mempengaruhi keputusan pembelian, oleh karena itu peneliti selanjutnya di harapkan dapat melakukan penelitian di perusahaan ritel lainnya, supermarket, departement store dan sebagainya.

\section{DAFTAR PUSTAKA}

Kotler, P. 2012. Marketing Management Eleventh Edition. Upper Saddle River: Prentice Hall International.

Sugiyono. 2017. Metode Penelitian Kuantitatif, Kualitatif, dan R\&D. Bandung: Alfabeta, CV.

Sunarto. 2018. Analisis Perilaku Konsumen Terhadap Keputusan Pembelian Handphone Xiaomi Redmi 3S. Jurnal Moneter.

Uma Sekaran. 2006. Metode Penelitiaan Bisnis. Jakarta: Salemba Empat. 